\title{
Distribution of Deposited Carbon in Carbon Brake Disc Made by Pressure-Gradient Chemical Vapor Infiltration
}

\author{
Jianxun Chen^ and Xiang Xiong \\ State Key Laboratory for Powder Metallurgy, Central South University, Changsha 410083, China \\ ^e-mail:jxchen@mail.csu.edu.cn \\ (Received February 3, 2007; Accepted March 16, 2007)
}

\begin{abstract}
The carbon brake discs were manufactured by densification the carbon fiber preform using PG-CVI technology with Propene as a carbon precursor gas and Nitrogen as a carrier gas. The densities of carbon brake discs were tested at different densification time. The results indicate that the densification rate is more rapid before $100 \mathrm{hrs}$ than after $200 \mathrm{hrs}$. The CTscanning image and the SEM technology were used to observe the inner subtle structure. CT-images show the density distribution in the carbon brake disc clearly. The carbon brake disk made by PG-CVI is not very uniform. There is a density gradient in the bulk. The high-density part in the carbon brake is really located in the friction surface, especially in the part of inner circle. This density distribution is most suitable for the stator disc.
\end{abstract}

Keywords : Carbon brake disc, CT-image, SEM, Density distribution

\section{Introduction}

Carbon/Carbon $(\mathrm{C} / \mathrm{C})$ composite has been widely used in aerospace industries, defense industries and commercial industries owing to its excellent properties of low density, high strength at high temperature, low thermal expansion, and capability of withstanding high temperature over 3000 ${ }^{\circ} \mathrm{C}$. For example, in defense industries, the key parts of missile nose tips, solid rocket motor throats et al. are manufactured from $\mathrm{C} / \mathrm{C}$ Composite [1-3]. These parts are for country safety. Therefore, the cost of making process is not a significant problem here. In the field of commercial industries, $\mathrm{C} / \mathrm{C}$ composite is widely being used in airplane for its excellent tribological and low-density properties [4]. With the price of energy and raw material increasing, it will become an essential way for reducing the cost of $\mathrm{C} / \mathrm{C}$ composite to look for more efficient manufacture technology.

It is will known that the main technology to manufacture $\mathrm{C} / \mathrm{C}$ composite is chemical vapor infiltration (CVI) approach $[5,6]$. The matrix carbon from CVI method is suitable well to be friction material for carbon brake disk [7]. But the densification and operation time is very long so that it becomes an obvious obstacle to expend its usage in commercial area.

To overcome this shortcoming, more and more researchers are devoting to look for the efficient technology. Ruiying luo reported [8] a new method to make the $\mathrm{C} / \mathrm{C}$ composite via the electrified preform producing directly heat CVI process. $\mathrm{He}$ got a high speed CVI densification process for $\mathrm{C} / \mathrm{C}$ composite (for example, after $80 \mathrm{hrs}$ densification, the bulk density of sample is up to $1.71 \mathrm{~g} / \mathrm{cm}^{3}$ ). Hyeok JE Jeong et al. reported [9] a densification of $\mathrm{C} / \mathrm{C}$ composite by pulse chemical vapor infiltration. They have studied the influence of several experimental parameters such as deposition temperature, evacuation time and gas introduction time and pulse number on the bulk density. Sundar Vaidyaraman et al. reported [10] a forced flow -thermal gradient CVI infiltration process to make $\mathrm{C} / \mathrm{C}$ composite. Although various $\mathrm{CVI}$ approaches have been tried, many experiment results have been opened, the majority of those research works were limited in laboratory. Therefore, those methods and results in CVI technologies cannot be used directly to make the industrial produces. Our previous work showed that [11] the Pressure-Gradient CVI process was an efficient approach to make the carbon brake disc for the commercial airplane B757 style. In that work, the deposition status of pyrolytic carbon in different parts of carbon fiber preform was investigated. It showed that the uniformity of carbon fiber preform is significant for the CVI process. The present study was focused on the pyrolytic matrix distribution in the full disc.

\section{Experimental}

The carbon fiber preform, needle-punched felt that often used to fabricate the aircraft brake disc, was utilized in present study. It is composed of continuous carbon fibers and chopped carbon fibers. The continuous carbon fiber is $12 \mathrm{~K}$ PAN based T-700 fiber from TOHO RAYON, Japan. The chopped carbon fiber is cut short of 12K-PAN based T700 


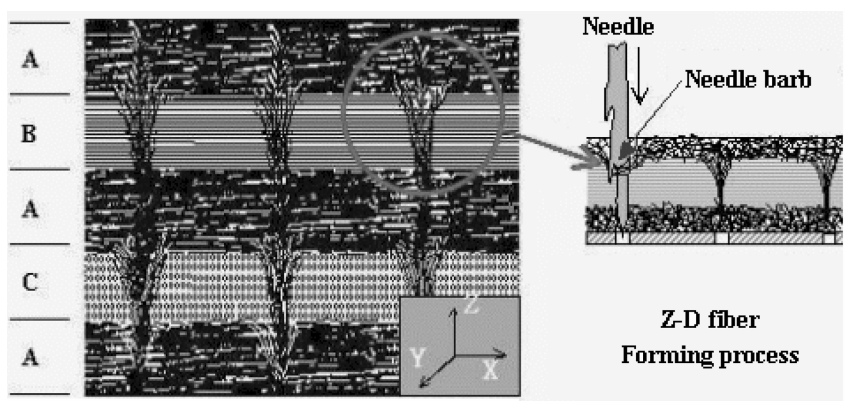

Fig. 1. Schematic of carbon fiber preform forming process.

from TORAY, Japan. The schematic diagram of needlepunched felt is shown in Fig. 1.

In Fig. 1 part $\mathrm{A}$ is the layer of a randomly oriented chopped carbon fiber mat, part B and $\mathrm{C}$ are the layers of continuous carbon fiber in $\mathrm{X}$ and $\mathrm{Y}$ direction respectively. During the needle punching process, many of needles, which penetrated vertically into each new superposed layer, passed through the layer of chopped fiber web firstly. Some of the clusters of chopped fibers were caught and drawn through the layer of the continuous fibers and the chopped fiber mat by the needle barbs, and formed the needled fibers or Zdirection fibers in the preform. When the needles were left up, the Z-direction fibers were leaved in the preform owing to the needle moving direction is in the direction of its barb. With the increasing of needle-punched times and depth, more and more Z-direction fibers were penetrated into the preform. The carbon fiber preform was fabricated by using a desired number of superposed layers connected by the mutual mechanical binding and interlacing between Z-direction fibers with other fibers (continuous or chopped fibers). Finally, the preform with a desired density of $0.65 \mathrm{~g} / \mathrm{cm}^{3}$ was cut in the form of $\phi 414 \times 190 \times 32 \mathrm{~mm}$.

After heat treated at $2100^{\circ} \mathrm{C}$, the preforms were placed in PG-CVI furnace and infiltrated by using Propene as a carbon precursor gas and Nitrogen as a carrier gas. The schematic drawing of PG-CVI furnace used in the present work is

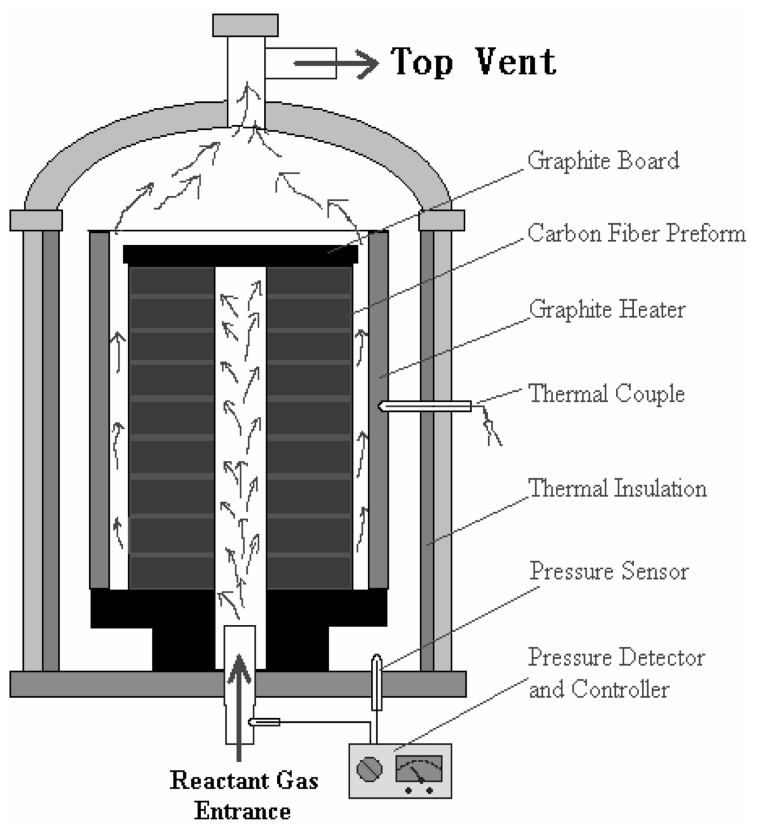

Fig. 2. Schematic of the PG-CVI furnace.

shown in Fig. 2. The ratio of Propene to Nitrogen was about $1: 3$. The flow rate was about $60 \mathrm{~L} / \mathrm{min}$. The densification process was performed at the temperature ranging from 850 to $900^{\circ} \mathrm{C}$ with a reduced pressure. During the densification process, the carbon precursor and carrier gases were fed into the PG-CVI furnace from the reactant gas entrance, and passed through the preforms, finally exhausted from the top vent.

At the initial stage of the densification process, the flow rate was only controlled for the high porosity in the preforms. Along with the densification process extending, the density of preforms were increased higher and higher, at the same time, the pressure gradient was formed gradually between inner and outer of the preforms. At this stage, the pressure was detected and controlled by the pressure detector and controller. After every $100 \mathrm{hrs}$ densification, the pre-
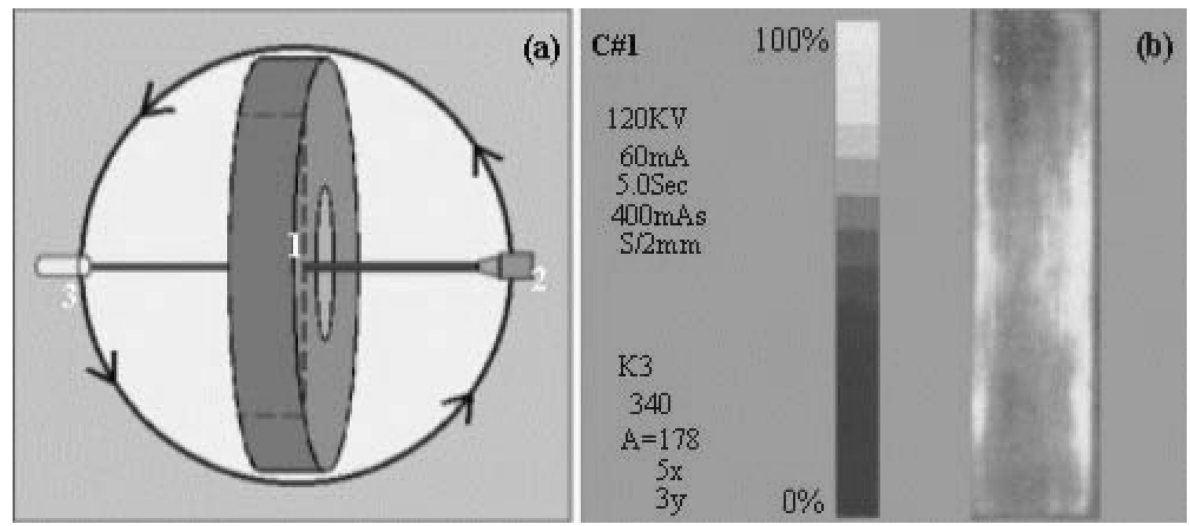

Fig. 3. Schematic diagram of experimental for CT-scanning measurement. (a) Scanner and acceptor (b) Scanning information showing in computer, 1. Carbon brake disc 2. Scanner 3. Acceptor 
forms were weighted one by one to get their density values. Finally, the carbon brake discs were heat treated at $2300^{\circ} \mathrm{C}$.

A physic CT apparatus for common used was employed to image the status of the deposited carbon in carbon brake disc. The schematic diagram of experimental apparatus is shown in Fig. 3. The carbon brake disc was set in the CT scanning field, a scanner and an acceptor at a desired position could turn continuously from $0^{\circ}$ to $360^{\circ}$ around the carbon brake disc in the same step, At the same time, a scanning beam scanned through the carbon brake disc one circle (See the Fig. 3(a)). The scanned information was collected by the acceptor and displayed in a computer screen (See Fig. 3(b)). Every internal image at the different scanning position in the carbon brake disc can be observed via the CT measurement without cutting the disc. All of the images along the different line positions from one side to other side were carried out under the condition of $120 \mathrm{KV}$ voltage, $80 \mathrm{~mA}$ current and $5.0 \mathrm{sec}$ scanning time.

To further prove the CT results, a carbon brake disk was cut and observed specifically by using a model of JSM6700F SEM equipment.

\section{Results and Discussion}

\subsection{Relationship of the density with the infiltration time}

It is well known that the main disadvantage of CVI technology is the long processing time. To reduce the price of carbon brake disc, it is an essential step to shorten the densification time. The PG-CVI technology is a prevalent method in practice industry. During the PG-CVI process, the growth rate and the deposit site of carbon matrix in carbon fiber preform will influence not only the densification time, but also the properties of brake disc. To test the deposit rate, the preforms were weighted after each $100 \mathrm{hrs}$ densification. Fig. 4 indicates the relationship of the average value of carbon brake disc densities $v s$ the densification time.

It shows obviously that the density of carbon brake disc increase with the densification time extending. From above result it can be obtained that the increasing rate of carbon brake disc density is higher in the initial stage of densification process (before $100 \mathrm{hrs}$ ). After $200 \mathrm{hrs}$, the densification rate becomes lower gradually. The main reason for this phenomenon is the following: at the beginning of densification process, the contacting and the bonding for carbon fibers in the preform contribute to the mechanical action, the porosity and surface-to-volume ratio in carbon fiber preform are higher. Therefore, there is not a significant resistance, such as crust, skin in the preform, which impede the carbon source gas flowing through the preform. So the densification rate for the earlier stage is strongly rapid. A. Becker and $\mathrm{K}$. J. Huttinger reported [12] that the deposition volume/deposition surface area ratio has a significant influence on the

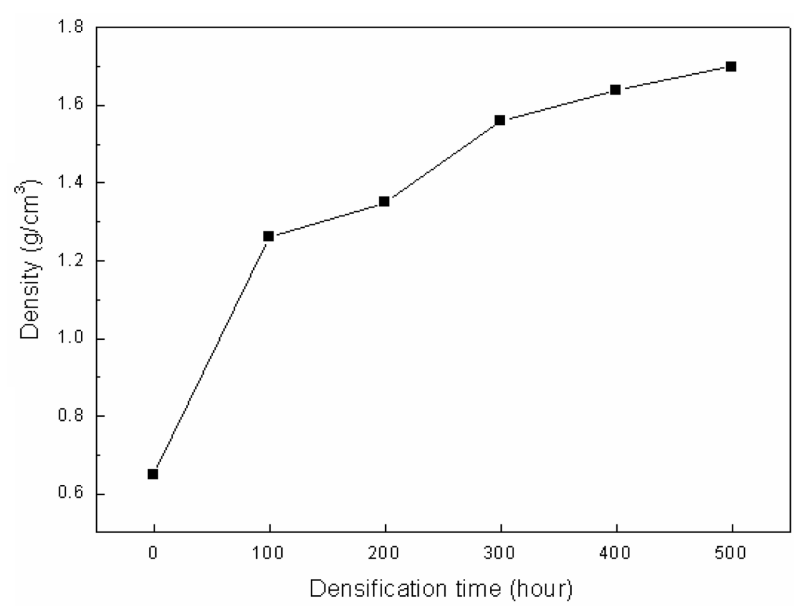

Fig. 4. Relationship of density vs densification.

overall pyrocarbon deposition rate. From Fig. 4, it can be figured out that the proportion of the deposited carbon in the earlier $100 \mathrm{hrs}$ is approximately $61 \%$. Then the proportion of the deposited carbon in the remained time (about $400 \mathrm{hrs}$ ) is only about $44 \%$. This result implies that the densification process in the earlier stage is significant for the entire CVI process.

\subsection{Distribution of pyrolytic carbon matrix in carbon brake disc}

In the process of producing carbon brake disc, the properties of disc have been tested frequently, such as density, graphitization, microstructure, etc.. Among them, the density value is a significant factor to decide the next process parameters during the CVI process. In practical industrial test, the value of density of carbon brake disc is acquired by testing the disc weight and size. All of these tested values only indicated the disc properties in appearance. It is impossible to get the information of deposited matrix carbon, such as the subtle structure, the distribution and the uniformity, without destroyed the carbon brake disc.

Carbon brake disc belonging to the $\mathrm{C} / \mathrm{C}$ composite is a porous material, the normal ultrasonic testing apparatus is not effective for the high ultrasonic attenuation in composite material. The X-ray scan apparatus used in industrial only get the plane image of the through-transmission. The inner image of carbon brake disc can be shown by the physic CT technology without destroying it.

Fig. 5(a) shows the scanning image picture of full size disc, Fig. 5(b) shows respectively the inner images at the line positions of 1, 4 and 7 in Fig. 5(a).

In the CT images shown in Fig. 5(b), the brightness areas are the high-density part in the carbon brake disc, the darkness areas are the low-density part at the line position of 1, 4 and 7 positions respectively. At the same time, the different degree of brightness is corresponding to the 


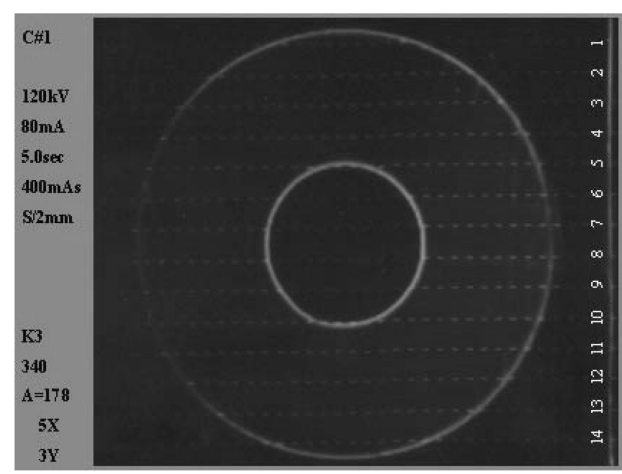

(a)

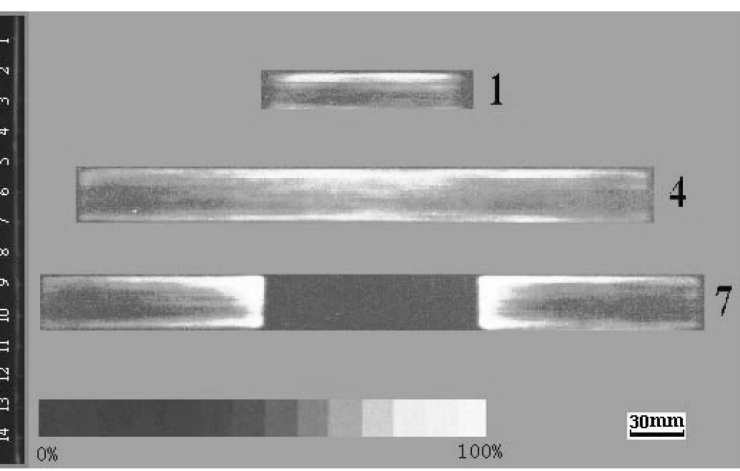

(b)

Fig. 5. CT image pictures of carbon brake disc: (a) Full size disc image and (b) Images at the lines of 1, 4 and 7.

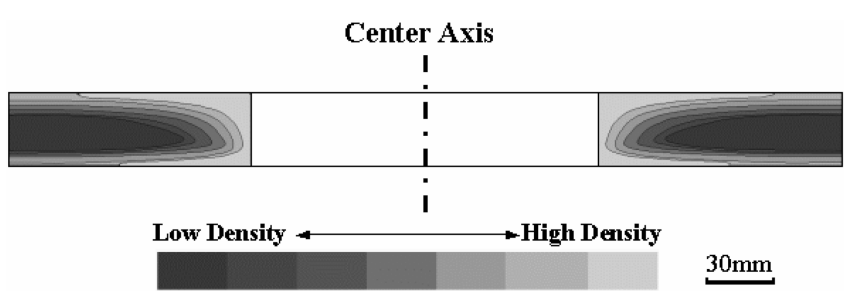

Fig. 6. Cross-section drawing of density distribution in carbon brake disc.

different density in the brake disc. In Fig. 5(b), the picture with the position 7 is just about the imagine scanning cross the disc center.

According to Fig. 5(b), the distribution drawing of different densities in the carbon brake disc is shown in Fig. 6. In Fig. 6, the different darkness degree implies the different density in the brake disc. High-brigthness degree means the high-density of densification carbon area.

Fig. 6 shows the distribution of density in inner of carbon brake disc clearly. It was found that there is a density gradient in carbon brake disc. The density of the brake disc close to the center axis is higher than close to the outer part. The highest density is nearby the surface of the inner hole.

The SEM measurement was carried out to test the deposited carbon structure at the high-density and the low- density areas. Fig. 7 shows the tested SEM photographs in different parts of high and low densities respectively.

In Fig. 7, it is obviously that the deposited carbon in the high-density area is more compact than in the low-density area. There is not a crack between carbon fiber and deposited carbon in the part of the high-density area. However, the deposited carbon around carbon fiber in the low-density area is less than in the high-density area, and is a loosen structure carbon. The surface crust coated on the disc is the main reason to reduce the densification rate, too.

Above results indicate that the carbon brake disk contains some residual porosity in the bulk. At the meanwhile, the high-density area is located in the outer of the brake disc, namely, in the part of the friction surface and the key torque

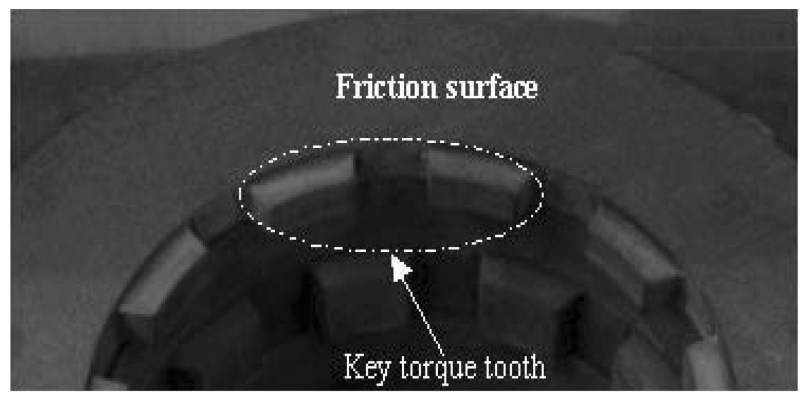

Fig. 8. Different part of carbon brake disc.
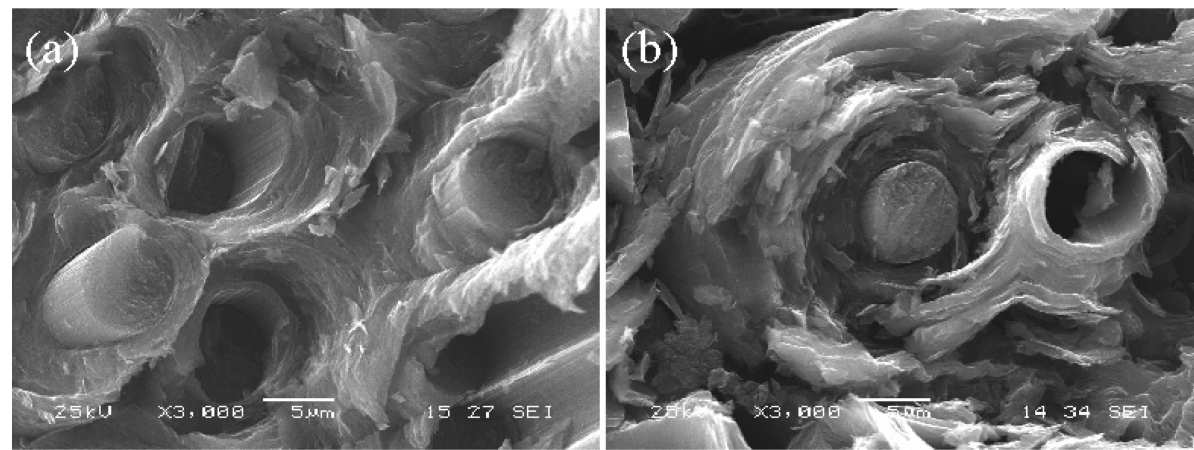

Fig. 7. SEM photographs of (a) high density and (b) low density. 
tooth. See Fig. 8.

In fact, the uniformity for $\mathrm{C} / \mathrm{C}$ composite is very significant. However, in every case, the composite display some residual porosity (typically $10-15 \%$ ) and a densification gradient from the inside to the outside [13]. Fortunately, for carbon brake disc made with $\mathrm{C} / \mathrm{C}$ composite, the high density in the friction surface means the high friction performance, the low wear rate and long life brake times. The part close to the center axis is the key toque tooth part for the stator disc, so the high density in this part imply the high strength for the key torque tooth. Certainly, this status is only about stator disc. For rotor disc, the result is an opposite status, namely, it is advantage for rotor disc that the highdensity part located in the outer of the brake disc. The advantaged densification result for rotor disc can be achieved by changing the direction of flowing gas during the CVI process.

\section{Conclusions}

The carbon brake discs were manufactured by the practice industrial approach of PG-CVI process. The properties of the carbon brake discs were tested. It was found that the carbon brake disk density increased with extending the densification time. Before $100 \mathrm{hrs}$, the density is higher up to $1.26 \mathrm{~g} / \mathrm{cm}^{3}$. After $200 \mathrm{hrs}$, the densification rate becomes lower gradually. The surface crust is the main reason to reduce the densification rate. CT-image results indicated that the carbon brake disc manufactured by PG-CVI process is not very uniform. The high-density area is near to the disc surface, especially in the part of inner circle. This density distribution of deposited carbon is most suitable for the stator disc.

\section{References}

[1] Byrne, C.; Wang, Z. Carbon 2001, 39, 1789.

[2] Shin, H.-K.; Lee, H.-B.; Kim, K.-S. Carbon 2001, 39, 959.

[3] Quli, F. A.; Thrower, P. A.; Radovic, L. R. Carbon 1998, 36, 1623.

[4] Buckley, J. D.; Edie, D. D. “Carbon-Carbon Material and Composites", New Jersey, Noyes publications, 1993, 275.

[5] Delhaes, P. Carbon 2002, 40, 641.

[6] Li, H.-J.; Hou, X.-H.; Chen, Y.-X. Carbon 2000, 38, 423.

[7] Lewis, J. S.; Lackey, W. J.; Vaidyaraman, S. Carbon 1997, 35(1), 103.

[8] Luo, R. Carbon 2002, 40, 1957.

[9] Hyeok, J. J.; Park, H. D.; Lee, J. D.; Park, J. O. Carbon 1996, 34(3), 417.

[10] Sundar, V.; Jack, L. W.; Agrawal, P. K.; Miller, M. A. Carbon 1996, 4(3), 47.

[11] Chen, J. X.; Huang, B. Y. Trans. Nonferrous Met. Soc. China 2004, 14(4), 34.

[12] Becker, A.; Huttinger, K. J. Carbon 1998, 36(3), 225.

[13] Bertrand, S.; Lavaud, J. F.; El Hadi, R. J. European Ceramic Society 1998, 18, 857. 